and surest form of tucking. I have been a little hesitant to use it in many cases on account of the unsightly reactions which I have seen, but one cannot talk to Californians without a renewed decision to give it a fair trial in cases where a moderate shortening is indicated. It seems impossible, however, that it can replace advancement where a large effect is desired. O'Connor often reinforces its effect by central tenotomy of the opposing muscle, but this has always seemed much less certain and accurate than recession. Certainly, O'Connor's fear of causing convergence insufficiency by a recession, whatever his models may show, is not borne out by practical experience with many recessions on the human eye, it being understood that the operation is carefully performed, and that the muscle is never set back more than $5 \mathrm{~mm}$.

\title{
LITERATURE
}

1. Guibor.-Arch. of Ophthal., Vol. II, p. 433, 1934.

2. Delord.-Arch. d'Ophtal., Vol. XXXVIII, p. 597, 1921.

3. Herzau.-Klin. Monatsbl. f. Augenheilk., Vol. XC. p. 551, 1933.

4. Peter.-Amer. Jl. of Ophthal., Vol. XVI, p. 481, 1933.

5. Cantonnet et al.-Le Strabisme. Paris, 1932.

6. Adler.-Ocular Physiology. 1933.

7. Mott.-Arch. of Ophthal., Vol. VIII, p. 858, 1932.

8. Wilkinson.-Arch. of Ophthal., Vol. XI, p. 471, 1934.

\section{FAMILIAL MACULAR DEGENERATION}

BY

Lieut.-Col. R. E. Wright, C.I.E., I.M.S.

SUPERINTENDENT, GOVERNMENT OPHTHALMIC

HOSPITAL, MADRAS

From time to time during the past 15 years macular degenerations have been met with here, in the course of routine fundus examinations, which presented certain peculiar similarities in appearance. It has been customary to use expressions such as "beaten brass or silver," "coppery sheen," etc. to describe the ill-defined macular fundus changes seen. I have for long regarded some of these cases as familial degenerations, as on rare occasions such appearances have been met with in more than one member of the same family. Moreover, they did not resemble any fundus change, with which we were familiar, connected with known pathological states, except, perhaps, the ill-defined changes which are sometimes seen after the resolution of bilateral subhyaloid haemorrhages. Owing to the difficulty which exists in obtaining accurate family histories from our South Indian patients, striking sibships are rarely forthcoming, but a family group met with 
recently seemed of sufficient interest and importance to record in some detail.

In September, 1933, Dr. R. J. Dyson, Chief Medical Officer, Madras and Southern Maharatta Railway, Madras, kindly asked me if I would examine the three sons of a station-master from Marmagoa. Their eyesight was failing rapidly and the father had consulted various eye specialists in other parts of India without satisfaction. He had one other child living, a girl who was apparently normal. On September 22, 1933, the father, of mixed Indian and Portuguese descent, came to the hospital with his three sons, aged 14, 12 and 11 years. They all presented defective visual acuity, an abnormally dull mental condition, and remarkable heads. These features were more marked in the eldest, less marked in the youngest.

Before describing each case in detail, the father's statement may be given. He said that neither he nor his wife had defective vision, nor had there been any consanguineous marriages, or defective vision in earlier life, for at least two generations. There was no venereal disease in the family. His wife was also of mixed Portuguese-Indian descent. Six children were born to them. The first-born died in the sixth year, the second-born died in the fifth year. He could not say for certain whether there was anything wrong with their eyes, nor if the shape of their heads was peculiar. Of the remaining four, the youngest, a girl of seven years of age, had no trouble with her sight. There was one miscarriage after the fourth child. The three boys had developed very bad sight, and as the trouble seemed to be progressive, he was very anxious about them.

The eldest living boy, aged 14 years, was attending elementary school till his eleventh year when he passed an examination in Portuguese. The school-master discovered on the examination day that the boy was holding the book very close while reading. From that year forward the sight had been getting steadily worse. On the date of the examination, three years back, when the defect of the eldest was noted, the second boy, then nine years of age, was examined and found to have bad vision also. His condition subsequently became steadily worse. 'The youngest boy sat for his examination at eight years of age and passed. No defect of vision was noticed at that time and an ophthalmic surgeon who then examined all three, said that the youngest was not suffering from defective sight whilst the other two were. In 1932 the youngest boy was found to be keeping the book close to his face while reading and from that time onwards his vision gradually failed. In his anxiety about the sight of the boys, the father consulted various doctors. In one hospital each boy received antispecific treatment. Elsewhere they were considered non-syphilitic. 
Both in 1931 and 1933 the blood of all three was examined at reliable laboratories and pronounced to have a negative Wassermann reaction. Night blindness was not a feature of the disorder, but the father noted dullness and mental apathy, especially in the case of the eldest boy.

Case I.-R.M., aged 14 years, a lanky boy for his age with a hatchet head and a dull apathetic expression, at first sight gave the impression of an oxycephalic defect, but on closer inspection this was obviously not so. The head was remarkable for its length and narrowness. There was undoubted mental deficiency, the patient was roused to attention with difficulty, and responded slowly and in a dull listless way to interrogation. The photographs and measurements appended give a better idea of the head than is conveyed by a written description; this is true, also, of the other members of the family.

Right and left eye vision $=6 / 60$, not improved with lenses. Corneae and pupil reflexes normal.

Right eye.-Refractive media clear. Fundus examination revealed a diffuse central retinitis, the whole macular region showing an ill-defined tarnished brass appearance. The fovea is of a smoky or dull chestnut colour according to the angle of view. Around the macular area is a fine pale mottling, some of the spots are larger (0.25 disc diameter) and irregularly dentate others rounded. The area of mottling extends for about 3 disê요 diameters temporal-wards of the macula. In places this change appears to be distributed along the vessels, but the mottling is deep to the capillary twigs. In the midperiphery and periphery there is no mottling, but towards the ora there are a few dark bluish patches. The disc is somewhat yellowish and pallid, but the vessels are not narrowed.

Left eye.-Very similar, but the change more marked. The fovea is of a dull chestnut colour surrounded by a paler dusky macula with a metallic sheen. 'The mottling is more irregular. A few spots are as large as half D. D., pale towards the centre and bluish at the margins; some are more opaque. The bulk of the change is inside a circle of $3 \mathrm{D}$. D. from the fovea, but there are a few bluish areas as in the other eye towards the ora. The vessels are not narrowed and do not suggest a tapeto-retinal type of degeneration.

Case II.-Wi., aged 12 years, was not so mentally dull nor so dolichocephalic as his elder brother.

Right and left eye vision $=6 / 60$, not improved with lenses.

Corneae of average size, pupil reflexes normal, no opacities in the media.

Fundus examination:-Right eye.-No foveal reflex, the macular area has the appearance of beaten brass. There is an 


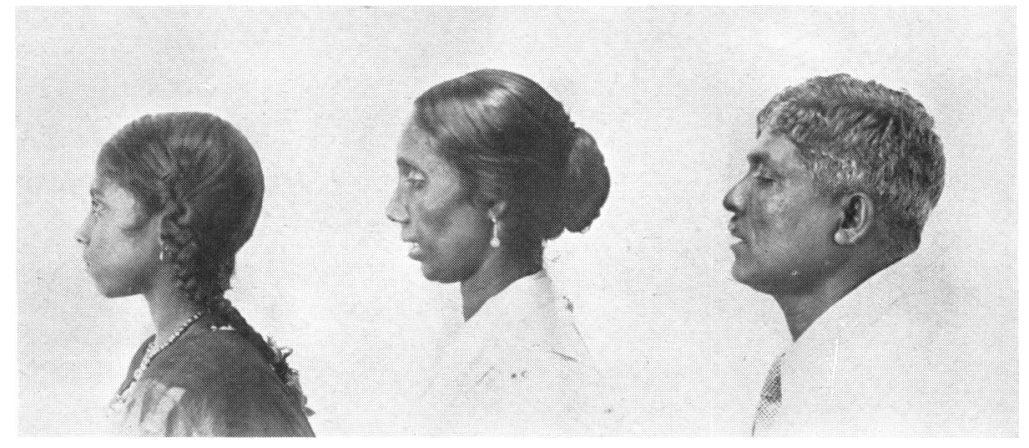

The Daughter, Mother and Father

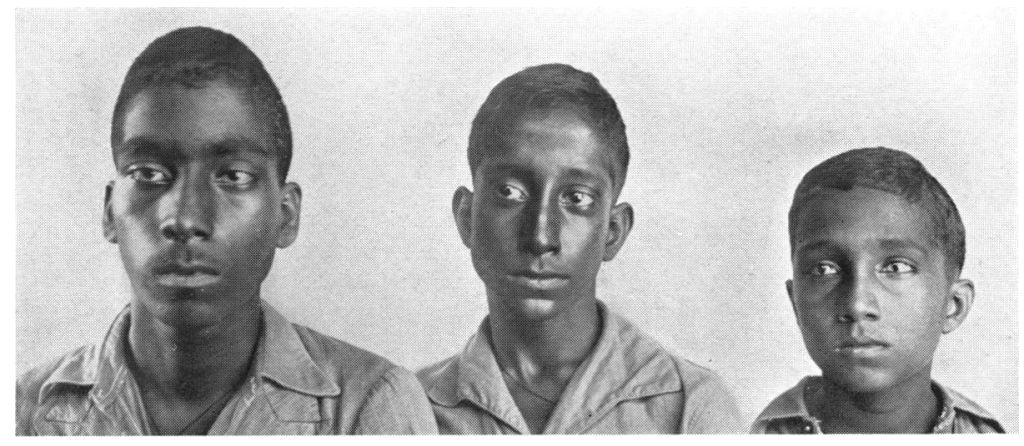

The Three Boys, Front Vieiv

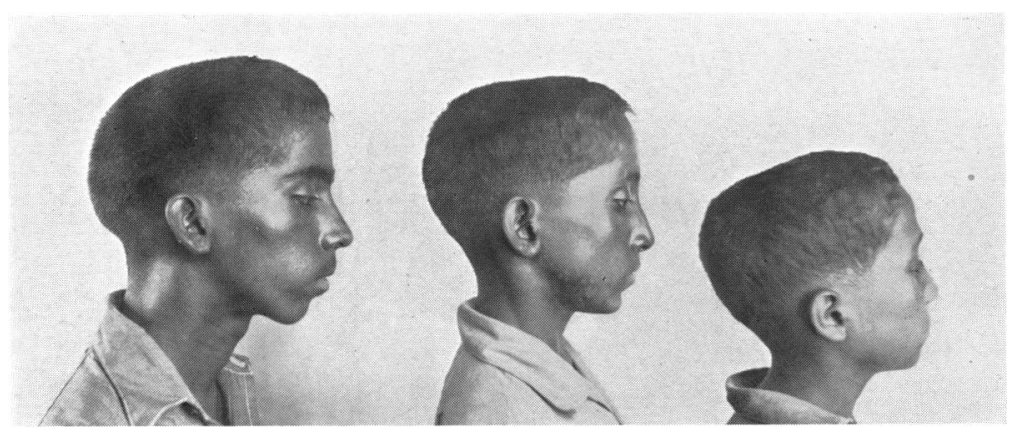

The Three Boys, Lateral View

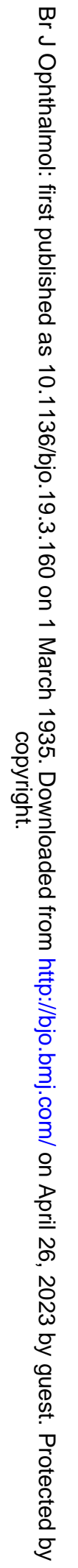




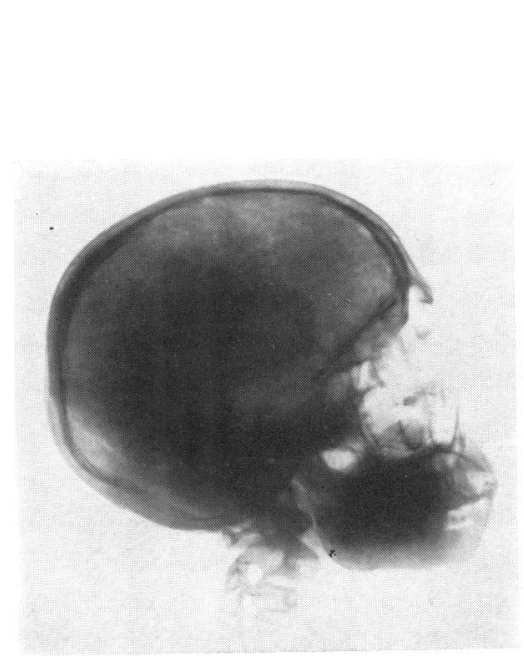

ThE FATHER

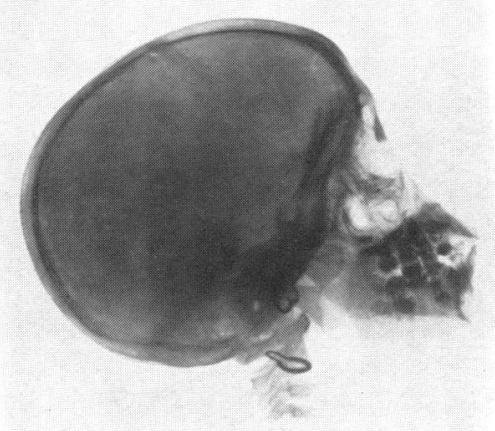

ThE DAUghter

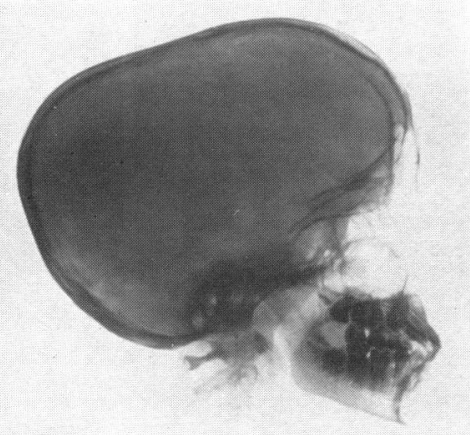

SECOND SON

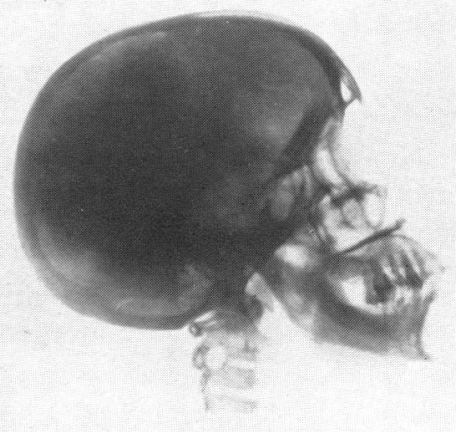

The Mother

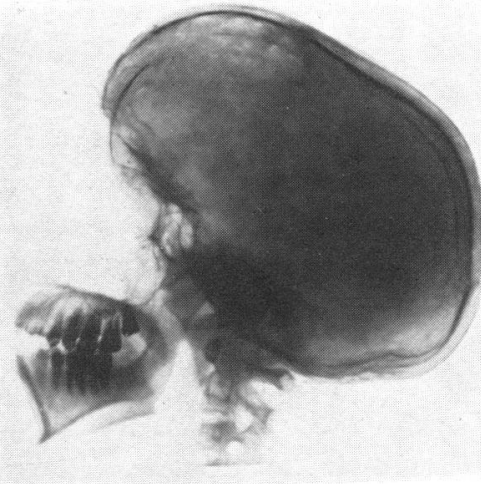

Eldest SoN

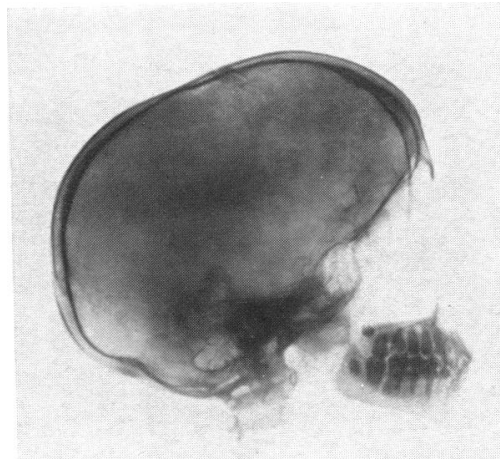

YOUNGEST SON

त 
indefinite mottling surrounding the macular area as far as the equator. It is very ill-defined, but gives a general impression of small round and larger irregular areas, some visible on account of their pale shade, others on account of their darkness, a faint mosaic or marbling effect. The distribution seems to have some relation to the vessels. The disc is of a somewhat yellowish colour, but definitely not atrophic. The vessels may be regarded as normal.

Left eye.-Fovea and macula same as in the right and also the mottling. There is definitely no pigment migration to be seen in connection with the mottled areas near the vessels, nor are there any changes in the vessels or discs to suggest a tapeto-retinal group disorder. As compared with the elder boy, the retinal change extends further towards the equator, without the bluish thinned areas near the ora.

Case 1II.-We., aged 11 years. Right and left eye vision $=6 / 60$, not improved with lenses. Corneae normal, pupil reactions normal, media clear.

Fundus examination :- Right eye.-Fovea of a maroon colour with a reflex present, quite an ordinary fovea for a deeply pigmented eye in a South Indian youth. The macular area is definitely smoky on direct view, with a marked brassy metallic sheen on lateral illumination. In the perimacular region there is a fine mottling much finer than in the other two boys, hardly discrete. It extends about three disc diameters to the nasal side of the disc and to a corresponding extent temporal-wards, up and down. There is no abnormality of the vessels and the disc is within normal limits.

Left eye.-Similar except that around the deep chestnut coloured fovea there is an area of paler smoky chestnut encircled by a ring of a deeper smoky tint. In this boy the mottling does not extend as far forwards as in the second boy. The fundus details in all three cases were indefinite and difficult to picture in words. The true nature of such appearances in isolated cases, without the support of a familial distribution, might readily be missed, even with an associated mental deterioration or anatomical peculiarity. In this respect the familial macular degenerations as a group differ from the tapeto-retinal degenerations since the latter can nearly always be recognized ophthalmoscopically, even in the non-pigmented and more centrally distributed types, by the disc and vessel changes. Dr. Koman Nayar agrees with me that similar central appearances are familiar to him, as occasional findings in the dark room which could not always be accounted for except by assuming a degenerative process.

Two years ago (1931) each of the two elder boys received 20 sulpharsenol injections without any improvement to the sight (and 
apparently without any definite damage, as the vision remained much the same after the course was finished).

The youngest boy, when examined by an eye doctor at the age of eight years, was said to have had normal vision. He still had good vision when the others were treated, nor did he develop poor vision till within the past year. Apparently in the case of all three there was not any defect in vision remarked on by parents or teachers till after the age of eight years. The previous family history was negative; the father, an intelligent man, said that he did not know of any relatives with bad sight on either side of the family, but it is quite likely that his knowledge of the maternal side was scanty. As a matter of routine the blood was examined here and all three boys and the father gave a negative Wassermann test.

The chief features of interest in this group of retinal defectives were : the reported escape of the girl (as yet, however, only seven years of age), and the associated progressive mental deterioration and dolichocephaly. In August, 1934, I had another opportunity of examining the whole family. As the father said on the occasion of the previous visit, the girl (now aged eight years) had nothing wrong with the vision, nor had the mother. The eye grounds of father, mother and girl were within normal limits. The girlo however, showed a concentric depression of the fields the outline lying between the $10^{\circ}$ and $20^{\circ}$ circles with a $3 \mathrm{~mm}$. white object at 2 metres. (The mother's fields were much fuller extending beyond the $20^{\circ}$ circle with a $2 \mathrm{~mm}$. white object at 2 metres.) They showed two peaks at axes 45 and 135 in the inferior quadrant, the peak in the left inferior temporal quadrant being symmetrical with that in the right inferior temporal quadrant and reaching to the $40^{\circ}$ circle in the form of a blunt cone. The inferior nasal peaks were similar, but only reached the $35^{\circ}$ circle. The girl did not appear

\begin{tabular}{|c|c|c|c|c|c|c|c|c|c|}
\hline AGE & Sex & $\begin{array}{l}\text { Glabello- } \\
\text { occipital } \\
\text { length }\end{array}$ & $\begin{array}{l}\text { Greatest } \\
\text { breadth }\end{array}$ & ${ }_{\text {index }}^{\text {Cephalic }}$ & $\mid \begin{array}{c}\text { Minimum } \\
\text { frontal } \\
\text { diameter }\end{array}$ & $\begin{array}{c}\text { Maximum } \\
\text { frontal } \\
\text { diameter }\end{array}$ & $\begin{array}{l}\text { Inter- } \\
\text { goinal } \\
\text { width }\end{array}$ & $\begin{array}{c}\text { Vertical } \\
\text { height }\end{array}$ & index \\
\hline 48 & Male - & 191 & 152 & 80 & 124 & 142 & 99 & 142 & 74 \\
\hline 43 & Female - & 172 & 130 & 76 & 101 & 118 & 87 & 134 & 78 \\
\hline 15 & Male - & 214 & 133 & 62 & 107 & 122 & 95 & 130 & 61 \\
\hline 13 & Male & 193 & 127 & 66 & 99 & 115 & 78 & 126 & 65 \\
\hline 12 & Male & 183 & 141 & 77 & 104 & 128 & 84 & 132 & 72 \\
\hline 8 & Female - & 175 & 137 & 78 & 100 & 118 & 78 & 129 & 74 \\
\hline
\end{tabular}

Part of the table of anthropometric measurements supplied by Dr. Gravely and Mr. Raghavan of the Madras Museum in August, 1934. 
to have a narrow elongated skull and the father seemed to be a square-headed individual, but the head of the mother was obviously of the long, narrow type. The actual conditions are shown in the reduced X-ray positives and in the anthropometric figures. The girl's measurements are not very different from those of the youngest boy. The girl is to report next year for further examination. The photographs and X-rays prints were kindly prepared for us by Captain Barnard and Dr. Pillai of the Barnard Institute of Radiology, Madras. Dr. Gravely of the Madras Museum has furnished me with the anthropometric measurements, and Drs. Vencatarangam Naidu and Vythinatha Iyer assisted in the collection of details necessary for this report.

\section{RISING FRONT BIFOCALS}

BY

\section{F. A. Williamson-Noble \\ LON DON}

THE ordinary form of bifocal glass possesses two disadvantages :-

1. That reading matter has to be held well below the horizontal plane in order to be clearly visible.

2. That the wearer is handicapped in going down steps and stairs, owing to the blurring and apparent displacement produced by looking at them through the reading portion of the glasses.

It occurred to me that these disadvantages might be overcome if an arrangement were provided by which the glasses could be lifted some $\tau$ to $8 \mathrm{~mm}$. above their ordinary position for then (1) the wearer could look almost straight ahead and yet be seeing through the reading portion of his glass, and (2) a space would be left below the glasses through which he could look down at steps and stairs and see them without the apparent displacement produced by looking obliquely through his presbyopic correction.

Various devices were tried and the most satisfactory and durable was found to be an adaptation of the "scholar's frame" type of bridge. This, as will be seen in Fig. 1, is attached to the spectacle frame by two sleeves in which it can slide up and down. The vertical members of the "scholar's bridge" are provided with a small nick which locks them in position when the glasses are in the high position. In actual practice though, the friction of the sleeves is sufficient to retain the spectacles in any desired position. With the glasses in the low position, they are indistinguishable in appearance from an ordinary pair, though when they are raised, the double bridge is, of course, apparent.

A second type of spectacle was made which rested on the bridge 